\title{
Perancangan Desintegration Tester Dilengkapi Sistem Pembuangan Air
}

\author{
Riska Riandani* $^{1}$, Wisnu Kartika ${ }^{2}$, Kuat Supriyadi ${ }^{3}$ \\ Program Studi D3 Teknologi Elektro-medis, Program Vokasi, Universitas Muhammadiyah Yogyakarta, Indonesia
}

INFO ARTIKEL

Alamat Web Artikel:

https://journal.umy.ac.id/index.php/

$\mathrm{mt} /$ article/view/11410

DOI:

https://doi.org/10.18196/mt.v3i1.11 410

Data Artikel:

Diterima:

03 April 2021

Direview:

15 Mei 2021

Direvisi :

10 Juni 2021

Disetujui :

30 September 2021

Korespondensi:

riska.riandani.d317@mail.

umy.ac.id

\begin{abstract}
ABSTRAK
Dalam pengujian tablet membutuhkan beberapa tahapan untuk memenuhi kriteria tablet yang standar, antara lain: (1) uji keseragaman sediaan; (2) uji keseragaman ukuran; (3) uji kerenggasan; (4) uji kekerasan; (5) penetapan kadar; (6) uji waktu hancur. Desintegration tester adalah alat laboratorium farmasi yang digunakan untuk menguji waktu hancur pada tablet. Tablet memenuhi standar jika tablet mampu hancur dalam suhu tubuh manusia yaitu $37^{\circ} \mathrm{C}$ dengan waktu kurang dari 15 menit. Dengan menggunakan metode penelitian mencelupkan obat ke dalam air dengan waktu kurang lebih \pm 20 kali dalam satu menit. Menggunakan waktu 15 menit untuk sekali percobaan dengan menggunakan tiga obat yang sama pada satu percobaan. Setelah proses selesai user menekan tombol saklar untuk proses pembuangan air. Sampel obat Paracetamol dan CTM yang dilarutkan menggunakan alat desintegration tester. Berdasarkan hasil akhir acuan diatas maka penulis membuat rancangan desintegration tester yang bekerja secara otomatis. Pada alat ini terdapat hasil berupa kelarutan obat pada chamber dengan hasil yang dijadikan patokan adalah waktu hancur obat tersebut.
\end{abstract}

Kata Kunci: : Desintegration Tester, Timer, Obat

\begin{abstract}
In testing, tablets require several stages to meet the standard criteria, including: (1) size uniformity test, (2) test the uniformity of the available, (3) hardness test, (4) coolness test, (5) time test destroyed, and (6) rate setting. Accordingly, a disintegration tester is a pharmaceutical laboratory tool used to test crushed time on tablets. A tablet meets the standard if the tablet is able to be destroyed at a human body temperature of $37^{\circ} \mathrm{C}$ in less than 15 minutes. In the research, the drug was dipped into the water approximately \pm 20 times in one minute, while a trial was conducted for 15 minutes and using the same three drugs in one trial. After the process is complete, the user presses the switch button for the water disposal process. The samples of paracetamol and CTM drugs were dissolved using a disintegration tester. Based on the final result of the reference above, a disintegration tester was designed with an automatic system. In this tool, the solubility of the drug in the chamber and the time took for the dissolution of the drug were used as references.
\end{abstract}

Keywords: Desintegration Tester, Timer, Dru

\section{PENDAHULUAN}

Perkembangan dan kemajuan peralatan kesehatan dewasa ini sudah sedemikian pesat. Hampir semua rumah sakit, klinik-klinik dan lembaga yang bergerak pada bidang kesehatan mengalami dan merasakan adanya dampak kemajuan peralatan kesehatan tersebut. Kemajuan peralatan kesehatan disebabkan karena perkembangan ilmu pengetahuan dan teknologi (IPTEK) yang berkembang sangat signifikan. Hal tersebut secara tidak langsung mendorong tenaga-tenaga kesehatan agar memiliki kemampuan yang unggul dalam melakukan dan melaksanakan tugas operasional guna tercapainya suatu tujuan yang optimal [1]. Salah satu kegiatan yang berkaitan dengan perkembangan peralatan medis yaitu pengujian kelayakan obat [2][3].

Obat merupakan salah satu aspek penting dalam upaya penyelenggaraan kesehatan[4]. Obat termasuk produk biologi yang digunakan untuk mempengaruhi atau menyelidiki sistem fisiologi atau keadaan patologi dalam rangka penetapan diagnosis, pencegahan, penyembuhan, pemulihan, kontrasepsi, dan peningkatan kesehatan untuk manusia [5][6]. Obat memiliki berbagai macam jenis 
dan fungsi. Salah satu jenis obat yang sering terdapat pada kehidupan sehari-hari adalah tablet. Tablet adalah sediaan padat yang mengandung bahan obat tanpa bahan pengisi [7]. Salah satu metode pengujian kelayakan tablet adalah uji waktu hancur.

Uji waktu hancur bertujuan untuk menetapkan kesesuaian batas waktu hancur yang tertera dalam masing-masing monografi. Selain itu waktu hancur tablet juga menggambarkan seberapa cepat lambat kondisi tablet hancur dalam cairan pencernaan manusia[7]. Pengujian dilakukan dengan cara meletakkan tablet pada kasa tahan karat dalam keranjang kemudian dimasukkan pada air yang memiliki suhu $37^{\circ} \mathrm{C}$. Obat pada keranjang dicelupkan pada air selama \pm 20 kali dalam kurun waktu tertentu[8]. Salah satu peralatan kesehatan yang digunakan untuk melakukan pengujian obat yaitu desintegration tester[8]. Seiring dengan perkembangan peralatan kesehatan dan kemajuan teknologi kebutuhan akan alat desintegration tester menjadi sangat penting guna mendukung tenaga medis dalam melakukan proses pengujian obat [9][10][11]. Peralatan desintegration tester yang beredar pada laboratorium masih belum dilengkapi dengan sistem pembuangan otomatis sehingga membuat user harus melakukan pembuangan air manual pada chamber. Hal tersebut secara tidak langsung membuat user bekerja beberapa kali dalam membuang air sisa proses pengujian, mengingat pada ssetelah pengujian obat selesai air harus dilakukan pergantian.

Berdasarkan permasalahan tersebut, penulis mencoba untuk membuat rancangan alat desintegration tester dengan pengaturan waktu adalah 15 menit yang bertujuan agar menciptakan alat desintegration tester yang memiliki nilai ekonomis dengan memanfaatkan komponen berbeda serta memudahkan user bekerja secara efektif dan efisien dengan menambahkan sistem pembuangan air secara mekanik menggunakan motor pump yang bertujuan memudahkan user melakukan pembuangan air pada chamber.

\section{METODE PENELITIAN}

\subsection{Alat}

Daftar peralatan yang digunakan pada proses perancangan alat.

Tabel 1. Alat

\begin{tabular}{|c|l|c|}
\hline No. & \multicolumn{1}{|c|}{ Nama Alat } & Jumlah \\
\hline 1. & Personal Computer & 1 \\
\hline 2. & Seperangkat Toolset & 1 \\
\hline 3. & Avometer Digital & 1 \\
\hline 4. & Bor & 1 \\
\hline 5. & Gerinda & 1 \\
\hline 6. & Solder & 1 \\
\hline 7. & Pemanas Lem & 1 \\
\hline
\end{tabular}

\subsection{Bahan}

Daftar bahan yang digunakan pada proses perancangan alat.

Tabel 2. Bahan

\begin{tabular}{|c|l|c|}
\hline No. & \multicolumn{1}{|c|}{ Nama Alat } & Jumlah \\
\hline 1. & Motor Pump DC 5V & 1 \\
\hline 2. & Tablet Obat & Opsional \\
\hline 3. & Minimum System ATMega 328P & 1 \\
\hline 4. & Sensor Suhu DS 18B20 & 1 \\
\hline 5. & Motor Power Window & 1 \\
\hline
\end{tabular}




\section{Riandani, Kartika, Supriyadi}

Perancangan Desintegration Tester Dilengkapi Sistem Pembuangan Air

\subsection{Rangkaian Keseluruhan}

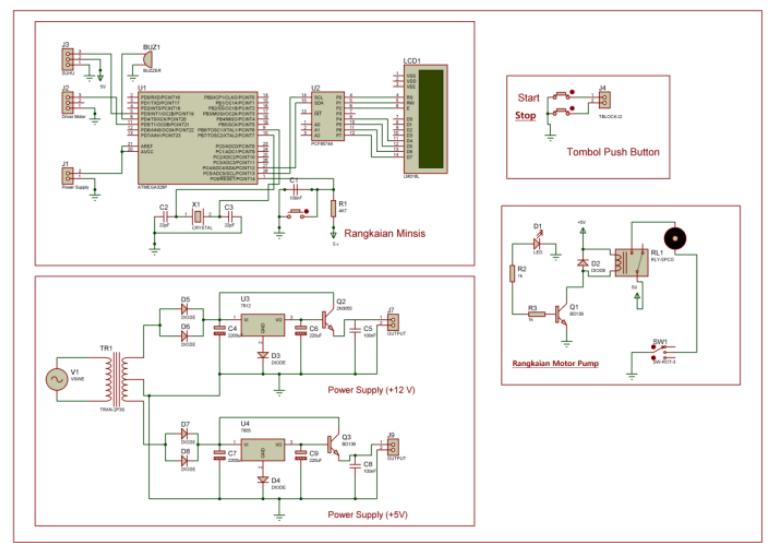

Gambar 1. Diagram Skematik Rangkaian Keseluruhan

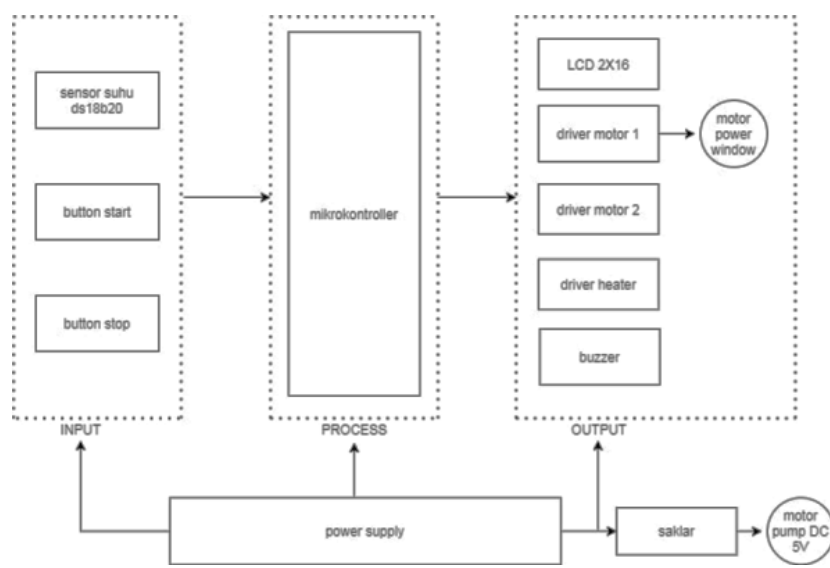

Gambar 2. Diagram Blok

\section{HASIL DAN PEMBAHASAN}

\subsection{Data Pengujian Waktu}

Tabel 3. Data Pengujian Waktu

\begin{tabular}{|c|c|c|}
\hline \multicolumn{3}{|c|}{ Pengambilan Data Waktu } \\
\hline $\begin{array}{c}\text { Pengujian } \\
\text { Ke- }\end{array}$ & Pada Alat & Stopwatch \\
\cline { 2 - 3 } & $\begin{array}{c}\text { Waktu } \\
\text { (Menit) }\end{array}$ & $\begin{array}{c}\text { Waktu } \\
\text { (Menit) }\end{array}$ \\
\hline 1 & 15,00 & 15,00 \\
\hline 2 & 15,00 & 15,00 \\
\hline 3 & 15,00 & 15,00 \\
\hline 4 & 15,00 & 15,00 \\
\hline 5 & 15,00 & 15,00 \\
\hline 6 & 15,00 & 15,00 \\
\hline 7 & 15,00 & 15,00 \\
\hline 8 & 15,00 & 15,00 \\
\hline 9 & 15,00 & 15,00 \\
\hline 10 & 15,00 & 15,00 \\
\hline Rata-Rata & 15,00 & 15,00 \\
\hline Persentase & 0 & 0 \\
Error (\%) & & \\
\hline
\end{tabular}

Medika Teknika : Jurnal Teknik Elektromedik Indonesia, Vol 03 No. 1, Oktober 2021 | 20 
Berdasarkan hasil pada Tabel 3 dapat dianalisa bahwa pada proses pengujian waktu yang dilakukan selama 10 kali pengambilan data, didapatkan hasil rata-rata pada alat rancangan dan alat uji yaitu 15.00 menit. Hasil tersebut menandakan bahwa waktu yang terdapat pada rancangan alat sesuai dengan alat uji.

\subsection{Data Pengujian Obat}

Tabel 4. Data Percobaan Pengujian

\begin{tabular}{|c|c|c|c|}
\hline \multicolumn{4}{|c|}{ CTM (Chlorpheniramine) } \\
\hline \multicolumn{2}{|c|}{ Pengujian Alat Asli } & Pengujian Rangcangan Alat \\
\hline $\begin{array}{c}\text { Pengujian } \\
\text { Ke- }\end{array}$ & Waktu (Menit) & $\begin{array}{c}\text { Pengujian } \\
\text { Ke- }\end{array}$ & Waktu (Menit) \\
\hline 1 & 2,24 & 1 & 2,04 \\
\hline 2 & 2,24 & 2 & 2,25 \\
\hline 3 & 2,24 & 3 & 2,32 \\
\hline 4 & 2,24 & 4 & 2,14 \\
\hline 5 & 2,24 & 5 & 2,05 \\
\hline Rata-Rata & 2,24 & Rata-Rata & 2,16 \\
\hline
\end{tabular}

Berdasarkan hasil pada Tabel 4 dapat dianalisa bahwa pengujian obat yang telah dilakukan didapatkan hasil bahwa alat berhasil melakukan proses perhitungan waktu hancur obat. Pada pengujian dengan menggunakan alat disintegration tester yang berada di Laboratorium Farmasi UMY didapatkan hasil yaitu pada pengujian pertama sampai kelima rata-rata waktu yang diperoleh bernilai 2 menit 24 detik. Sedangkan pada perancangan alat didapatkan hasil pengujian dengan rata-rata waktu 2 menit 16 detik. Selisih rata-rata yang didapat antara alat asli dan alat rancangan yaitu 0,8 detik. Hal tersebut dikarenakan oleh beberapa faktor seperti komposisi penyusun obat yang berbeda, kondisi obat yang digunakan, serta faktor luar seperti suhu ruangan dan kelembaban.

Waktu hancur obat sangat berpengaruh dalam proses biofarmasi dari obat, agar komponen obat sepenuhnya tersedia untuk diabsorsi dalam saluran cerna. Maka dari itu obat juga harus memiliki kekerasan yang cukup yang sesuai dengan persyaratan yang ada, karena semakin kecil presentase kelarutan obat dari seuatu tablet maka semakin baik efek yang diberikan tubuh oleh tubuh. Pada Laboratorium Farmasi UMY suhu dan kelembaban sudah disesuaikan dengan standar penyimpanan obat, sedangkan pada saat pengambilan data menggunakan perancangan alat suhu sekitar alat belum sesuai dengan standar penyimpanan obat. Berdasarkan hasil yang telah didapat maka obat dinyatakan masih layak untuk dikonsumsi karena obat larut sebelum mencapai 15 menit.

\section{KESIMPULAN}

Berdasarkan hasil penelitian yang dilakukan dapat disimpulkan bahwa sistem pembuangan air yang disusun oleh perancang hanya bisa membuang air sebesar $80 \%$, karena dimensi motor pump memiliki jarak antara dasar chamber dengan lubang pembuangan motor. Selanjutnya pengujian data waktu hancur didapatkan selisih antara perancangan alat dan alat uji yaitu obat Promag sebesar 6 detik dan obat CTM 8 detik.

\section{DAFTAR PUSTAKA}

[1] A. Shinta, "friability tester," pp. 1-4, 2019.

[2] H. R. Fajrin, U. Zakiyyah, and K. Supriyadi, "Alat Pengukur Ph Berbasis Arduino," Med. Tek. J. Tek. Elektromedik Indones., vol. 1, no. 2, 2020, doi: 10.18196/mt.010207.

[3] M. Safitri, W. D. Iswara, and T. Harjono, "Blood Bag Shaker Dilengkapi Pemilihan Kecepatan Motor," Med. Tek. J. Tek. Elektromedik Indones., vol. 1, no. 2, 2020, doi: 10.18196/mt.010208.

[4] D. A. Ade Maria Ulfa1, Nofita1, "Analisa uji kekerasan, kerapuhan dan waktu hancur asam mefenamat kaplet salut generik dan merek dagang," vol. 1, no. 2, pp. 59-68, 2018.

Medika Teknika : Jurnal Teknik Elektromedik Indonesia, Vol 03 No. 1, Oktober $2021 \mid 21$ 


\section{Riandani, Kartika, Supriyadi}

Perancangan Desintegration Tester Dilengkapi Sistem Pembuangan Air

[5] E. Loniza, H. Habiburrahman, and S. Ariwibowo, "Prototype Injeksi Insulin Pump Dengan Control Panel Arduino Uno," Med. Tek. J. Tek. Elektromedik Indones., vol. 1, no. 2, pp. 15, 2020, doi: 10.18196/mt.010206.

[6] N. H. Wijaya, B. Untara, and I. Khoirunnisa, "Monitoring Tekanan Gas Medis Pada Instalasi Gas Medis Rumah Sakit," Med. Tek. J. Tek. Elektromedik Indones., vol. 1, no. 1, pp. 2-7, 2019, doi: 10.18196/mt.010104.

[7] M. Ahmad Faizin, Hj. Her Gumiwang Ariswati, ST, MT, Tri Bowo Indrato, ST, "disintegration tester," 2014.

[8] C. D. Yanti, K. Kesehatan, P. K. Surabaya, and J. T. Elektromedik, "Desintegration Tester Berbasis Mikrokontroler AT 89s52," pp. 1-79, 2011.

[9] E. W. Ningsih, H. R. Fajrin, and A. Fitriyah, "Pendeteksi Hemoglobin Non Invasive," Med. Tek. J. Tek. Elektromedik Indones., vol. 1, no. 1, 2019, doi: 10.18196/mt.010102.

[10] E. Loniza and I. Syabani, "Portable Turbidimeter Dilengkapi Penyimpanan Data Berbasis Arduino," Med. Tek. J. Tek. Elektromedik Indones., vol. 1, no. 1, 2019, doi: 10.18196/mt.010103.

[11] H. R. Fajrin, M. R. Ilahi, B. S. Handoko, and I. P. Sari, "Body temperature monitoring based on telemedicine," J. Phys. Conf. Ser., vol. 1381, no. 1, 2019, doi: 10.1088/17426596/1381/1/012014. 